\title{
The influence of ontological and epistemological stance on educators' view towards human governance
}

\begin{abstract}
The purpose of this study is to explore the accounting educators' views toward the principles of human governance and the influence of ontological stance (or worldviews) and epistemological stance (view of knowledge) on their view. The data was collected using questionnaires and semistructured interviews. 90 accounting educators from Malaysian public universities had responded to the questionnaire and 28 had been involved in the interview. All variables (except demographic information) were measured based on 5-point Likert scales ranging from strongly disagree (1) to strongly agree (5). The descriptive analysis and Spearman's rank order correlation are used for analysis. The generic steps analysing are used for qualitative inquiry proposed by Creswell (2003). The finding revealed that accounting educators view human governance as a framework of good conduct of human being which emphasized both spiritual and physical well beings. There are positive medium correlations between ontological stances and educators' view towards the concept of human governance as good governance. There are only positive small correlations between epistemological stances towards the educators' view of human governance as good governance. This study provides new additional literature on ethics and empirical evidence on the concept of human governance.
\end{abstract}

Keyword : Human governance; Ontological stance; Epistemological stance 